\title{
Research on Development of Ancient Town Tourism from the Perspective of Low Carbon Economy
}

\author{
Yingli Kong \\ Henan Polytechnic, Zhengzhou, 450046, China
}

\begin{abstract}
In the critical period of Chinese economic transition, the development of ancient town tourism, as a highlight and hotspot in the current tourism industry in China, should seek for a kind of new tourism pattern featured by low pollution and low energy consumption based on the perspective of low carbon economy, so as to lead the development of ancient town tourism to sustainable development. Therefore, the author first made an introduction to the theory of low carbon economy in this paper, followed by an analysis on a series of issues existing in the current development of ancient town tourism. At last, the author proposed that we should reposition and implement development activities of ancient town tourism based on the theory of low carbon economy, so as to promote scientific and feasible development of ancient town tourism.
\end{abstract}

Key words: low carbon economy, low carbon tourism, ancient town tourism, tourism development

\section{Introduction}

There are a variety of ancient towns in China. They are historical remains of magnificent Chinese culture, containing abundant folk customs. They have already become key points and highlights in the development of the current tourism industry in China. However, old-fashioned philosophies of ancient town tourism development in China lead to unfavorable development trend of this type of tourism, especially for ecological environmental pollution or destruction in different degrees caused in the development process of ancient town tourism. Therefore, we think that we should adhere to a kind of philosophy currently advocated by China and other countries - low carbon economy to review the development of ancient town tourism, so as to promote sustainable development of ancient town tourism.

\section{Theoretical summary of low carbon economy}

The concept of low carbon economy was proposed at the earliest by Britain in the white paper of governmental energy in 2003. However, the similar philosophy of low carbon economy was proposed in the period of two sessions in 2010, namely to properly complete ecological protection and realize sustainable economic development. In fact, the fundamental objective of proposing the philosophy of low carbon economy is to make response to increasingly severe climate warming. This philosophy stresses to utilize all kinds of technical innovations and systems to develop new energy resources based on advanced philosophies of sustainable development, so as to make the economic development pattern to become a brand new pattern featured by low pollution, low energy consumption and low emission. It requires to establish a new production mode and consumption pattern and to adapt to the low-carbon energy system, low-carbon technical system and low-carbon industrial structure. Moreover, it is also necessary for a matched system of policies and laws and a complete market mechanism for coordination. Its essence is to realize technical renewal and innovation, so as to promote sustainable development of human society and economy. Generally speaking, low carbon economy 
should comply with development laws of market economy, realize adjustment and innovation to economic structure based on the maintenance of the existing living standards of people, improve the utilization of energy resources, and realize dislocation development between economic growth and energy consumption.

\section{Analysis on current development situation of Chinese ancient town tourism}

\subsection{Connotation and type of ancient town}

Up to now, ancient town is a generic term of ancient houses remained in a relatively complete way. It includes all kinds of ancient cities, ancient villages, ancient towns and some ethnic villages. After historical development over the years, these ancient towns are all of regional characteristics and cultural connotation. They are one of the most exciting tangible cultural heritages in Chinese traditional architecture.

According to different cultural backgrounds and historical regions, ancient towns can be divided into the following types: glorious Hui-style ancient villages, earthy northwestern ancient villages, delicate waterside ancient villages, noble northern courtyard buildings, bardian Lingnan ancient villages, romantic southwestern ancient villages, characteristic Nanzhao ancient villages and dynamic Xiangqian ancient villages. In most cases, these ancient towns are built on different landforms, such as mountainous regions, plains and hills. They are models of integration of antique humanity and the nature.

\subsection{Issues related to development of ancient towns}

At present, most development patterns of Chinese ancient town tourism rested on the lower level of sightseeing, for instance, unilaterally advocate the protection of charms of ancient towns, lack follow-up supervision after the preparation for the protection plan, and take the experience in folk-custom human feelings as main attractive point. Apparently, this kind of ancient town tourism development is a development pattern of high consumption, heavy pollution and low benefit. Its carbon emission far exceeds normal and standard value in the tourism industry. As a result, it is not optimistic for the current development situation of ancient town tourism. Main issues are shown as follows: i) the homogenization issue of tourism development; that is to say, the development of ancient town tourism lacks necessary difference, resulting in inadequate market competition of the development of ancient town tourism. Their themes and products often have many similarities. Moreover, service and marketing are relatively simple, lacking characteristics; ii) excessive commercialization trend; although the development of ancient town tourism cannot be separated from the nature of business, the present development of ancient town tourism is excessively inclined to the nature of business, eroding the original natural style and features and cultural environment; iii) relatively serious environmental destruction; the current development of ancient town tourism lays much emphasis on economic benefit. Moreover, the consciousness of protection and protective measures are insufficient, resulting in destructive damages to ancient towns in the process of tourism development; iv) cultural damage; the current development of ancient town tourism will cater to market demands sometimes and perform modern reconstruction of ancient towns, so as to make the development of ancient town tourism to loose the original vitality and culture of ancient towns, especially for extreme incoordination against remained ancient towns; and v) incomplete facilities matched; the current development of ancient town tourism always looks at the lower leveled sightseeing, lacking all-round cultural experience. Moreover, matched facilities are incomplete and difficult to form strong attraction. 


\section{Ancient town tourism development from the perspective of low carbon economy}

\subsection{Necessity of ancient town low carbon tourism development}

The development of ancient tow tourism has already become a noticeable focus in the Chinese tourism market. It is a systematic project involving several operation and management departments. It is necessary for us to make innovations to its philosophy and thinking, so as to promote sustainable development of ancient town tourism. Here, we discussed the development issue of ancient town tourism mainly based on the perspective of low carbon economy. This is a brand new philosophy, which can provide new thinking and pattern to the development of ancient town tourism, namely to turn the development of ancient town tourism to a kind of low-carbon tourism development pattern.

In fact, the concept of low carbon tourism appeared at the earliest in the tourism field in 2009. With a long history, China's tourist circle was relatively late in terms of the research on ancient town low carbon tourism, failing to form a complete cognitive system. However, we have already clearly realized the necessity to introduce the philosophy of low carbon economy into ancient town tourism. The reason is that it is the fundamental impetus and important guarantee of both the development of Chinese ancient town tourism and sustainable development. Low carbon tourism has already become a kind of green and environmentally-friendly tourism pattern at present. It lays particular emphasis on reduction to the emission of greenhouse gases and organic combination of resources and environmental protection. Therefore, we made a survey on the development of ancient town tourism from the perspective of low carbon economy, so as to provide opportunities and entry points of transformation and upgrading of ancient town tourism development. This is beneficial for promoting the transformation of Chinese ancient town tourism industrial structure from extensive pattern to intensive pattern and improving economic benefits, social benefits and comprehensive benefits of the development of ancient town tourism.

\subsection{Specific approaches for the development of ancient town low carbon tourism}

The development of ancient town tourism should be based on the philosophy of low carbon economy. At present, it is still confronted with some issues, such as weak low carbon consciousness of tourism participants, inadequate funds and low carbon tourism infrastructures, backward management of ancient towns, overproof carbon footprints of tourists, single energy structure and slow promotion of low carbon technologies. However, we should take certain measures to eliminate these adverse factors and promote the development of ancient town tourism to transform into a low carbon pattern.

\subsubsection{Set up and popularize the philosophy of low carbon tourism}

Chinese ancient towns are under the influence and restraints from natural conditions and traditional thoughts. Residents in these ancient towns are relatively backward and conservative in terms of thinking. We must break through this closed state, promote the concept of low carbon tourism by vigorous advocacy, and allow residents in ancient towns to feel different tourism knowledge and tourism patterns. Therefore, we should set up and popularize the philosophy of low carbon tourism and positively establish an industrial system of ancient town low carbon tourism. That is to say, we should take full advantage of local low carbon tourism resources and reduce the emission of greenhouse gases in the development process of ancient town tourism, letting residents in ancient towns practically feel tangible benefits and benefits of the low carbon tourism development pattern. 
However, the philosophy of low carbon tourism is still in a closed state. For residents in ancient towns, this philosophy still belongs to a new word. We should multi-directionally advocate the philosophy of low carbon and develop low carbon activities by virtue of the publicity function of public opinions, enabling residents in ancient towns to have all-round contact with the contents and modes of low carbon tourism. Certainly, the establishment and popularization of the low carbon tourism philosophy needs joint participation of the government, tourists, tourism enterprises and other related persons. Moreover, we should give correct guidance to the development of ancient town tourism toward the transformation and development of a low carbon pattern.

\subsubsection{Research, develop and promote low carbon tourism techniques}

For the current development of ancient town tourism, to really realize the low carbon tourism pattern, we should research, develop, promote and utilize all kinds of low carbon technologies from the perspective of technology and construct a clean and high-efficiency ancient town energy supply system. Then, the government should play a key role in the research, development and promotion process of such technologies. The government should invest more fund supports and policy supports into the development of ancient town low carbon tourism pattern. This is completely compatible with the fundamental realities of China. Under the great supports from the government, ancient towns should take full advantage of their advantages in economic development to promote further development of ecological agriculture and circular economy pattern. In some cases, costs are relatively high for the utilization of low carbon techniques. However, ancient towns can still rely on governmental allowance, rewards or other means to utilize all kinds of low carbon technologies, so as to eliminate various kinds of living pollutants for residents in ancient towns as much as possible, realize the final objective of energy conservation and emission reduction for low carbon technologies, maximize the utilization of all kinds of low carbon resources and be beneficial for healthy, stable and sustainable development of ancient town tourism development. Therefore, we should properly research, develop and utilize low carbon technologies in the development process of ancient town tourism and positively explore for a characteristic and diversified energy supply system for ancient towns.

\subsubsection{Set up and complete relevant low carbon policies}

The development of ancient town tourism should adhere to the pattern of low carbon development. Moreover, the government also needs to make relevant low carbon policies and allow the development of ancient town tourism to be under guidance and support of new policies, so as to establish a long-term mechanism for ancient town low carbon tourism. That is to say, the government should take the lead in the development process of ancient town low carbon tourism, especially for low carbon tourism development policies and system innovation according to the philosophy of scientific outlook on development. Moreover, the government should also guide and lead tourism enterprises in ancient towns, ancient towns and residents \& tourists in ancient towns to pay attention to the objective and responsibility of energy conservation and emission reduction, and establish relevant evaluation systems, so as to implement strict punishment systems for those tourism enterprises and related persons failing to reach the standards for energy conservation and emission reduction. Moreover, the government should also make continuous improvement to relevant emission reduction management systems and mechanisms, especially for the formulation and perfection of development planning 
and industrial policies of the tourism industry, so as to radically control carbon emission and guarantee the transformation and transition of ancient town tourism development from extensive pattern to sustainable development mode. Thus, it is necessary for the government to combine advanced experiences in overseas countries and actual conditions in China and intensify the function of macroscopic readjustment and control, especially for the acceleration of establishment of laws and systems for low carbon tourism, so as to further standardize governmental behaviors and behaviors of tourism enterprises and really provide system guidance and policy support to the development of ancient town tourism toward the low carbon pattern. Certainly, the formulation and implementation of this low carbon policy requires positive participation of enterprises. They should form saving-type production systems based on such policy. Moreover, tourists should transform the consumption mode and establish the low carbon consumption structure. Such low carbon policy can really give play to the guidance function, especially for the function of carbon sink and the construction of a cleaner development mechanism.

\section{Conclusion}

To sum up, the development of ancient town tourism is an emerging tourism industry. During its development, it also brought forth pollution and other ecological issues. Therefore, we should open up a new pattern for the development of ancient town tourism based on the perspective of low carbon economy. To this end, it is necessary for us to promote the production, consumption and living modes under the concept of low carbon, create a favorable environmental atmosphere for the development of low carbon tourism, prepare and perfect policies and measures for the development of low carbon tourism products and strengthen marketing and foreign cooperation \& exchange of low carbon tourism products, so as to make people to really promote the low carbon development of ancient town tourism under the guidance of low carbon life concept and the philosophy of low carbon tourism.

\section{References:}

[1] Hou Wenliang, Liang Like and Si Dongge, Research on Basic Concept System of Low Carbon Tourism [J], Journal of Anyang Normal University, 2010, 25 (1): 13-17;

[2] Jiang Xiaohua and Lu Yongzhong, Research on Development Strategies for Tourism in Tengchong of Yunnan from the Perspective of Low Carbon Tourism [J], Inquiry into Economic Issues, 2011 (5): 186-190;

[3] Li Xiaoming, Zhang Zhaogan and Lin Chaoli, Research on Construction of Low Carbon Tourism Community based on the Background of Low Carbon Economy - with Feida Village in Danyang City of Jiangsu Province as an Example [J], Henan Science, 2010 (1): 626-630;

[4] Tang Chengcai, Zhong Linsheng and Cheng Shengkui, Research on Connotation and Sustainable Development Strategies of Chinese Low Carbon Tourism [J], Economic Geography, 2011 (5): 862-867;

[5] Yu Han and Wang Zhaofeng, Research on Tourism Development of Xiangxi Ancient Town based on Low Carbon Economy [J], Rural Tourism, 2010 (3): 71-73. 